\title{
Hubungan antara Pemimpin Abusif dan Organizational Citizenship Behavior: Apakah Agreeableness sebagai Pemoderasi?
}

\author{
Edi Cahyono \\ Program Pascasarjana, Institut Agama Islam Negeri Salatiga, Jl. Lingkar Selatan Km 2, Salatiga, 50716 \\ E-mail: edicahyono448@gmail.com
}

\begin{abstract}
The purpose of this paper is twofold. First, to examine the relationship between employee's perception of abusive leader and their organizational citizenship behavior. Second, to investigate the moderating role of agreeableness on this relationship. Data were collected from 200 employee's working at Rural Bank (BPR) in Surakarta, Indonesia through online questionnaires. The finding of the study confirms that abusive leader is negatively related to subordinates' organizational citizenship behavior. The study also reveals that agreeableness moderated the relationship between abusive leader and subordinates' organizational citizenship behavior.
\end{abstract}

Keywords-: Abusive Leader; Organizational Citizenship Behavior; Personality; Agreeableness.

\section{PENDAHULUAN}

Fenomena pemimpin abusif di Indonesia saat ini masih menjadi isu yang penting untuk diteliti. Hal ini dikarenakan, Indonesia termasuk dalam kategori negara dengan dimensi budaya jarak kekuasaan yang tinggi (Hofstede, 1983). Di negara dengan budaya jarak kekuasaan tinggi, seorang pimpinan perusahaan mempunyai kekuasaan dan kontrol yang tidak terbatas terhadap karyawannya, sehingga perilaku abusif yang ditampilkan oleh pimpinan terhadap bawahan berpotensi lebih besar untuk terjadi. Studi terdahulu mengindikasi bahwa karyawan di Indonesia memiliki pengalaman pernah diperlakukan abusif oleh pimpinannya di perusahaan (Hancock, 2000). Praktik pemimpin abusif relatif sering ditemukan pada perusahaan perbankan yang berskala kecil, misalnya pada bank perkreditan rakyat (Cahyono \& Abdullah, 2021). Hal ini dapat memberikan dampak buruk apabila tidak segera diminimalisir dan diberikan stimulus dengan baik.

Meskipun fenomena praktik pemimpin abusif sangat berpotensi terjadi pada perusahaan di Indonesia, namun masih relatif sedikit penelitian yang mengkaji tentang topik tersebut di Indonesia (Cahyono et al., 2020b). Beberapa studi terdahulu menjelaskan bahwa pemimpin abusif dapat menyebabkan dampak buruk terhadap karyawan di perusahaan, misalnya: tingkat kepuasan kerja yang rendah (Jiang et al., 2016; Cahyono et al., 2020a), tingkat kinerja dan organizational citizenship behavior (selanjutnya disingkat OCB) yang rendah (Zellars et al., 2002; Haryanto \& Cahyono, 2019; Cahyono et al., 2020b), bahkan tingkat turnover intention yang tinggi (Tepper et al., 2006; Rodwell et al., 2014; Pradhan et al., 2018; Tepper et al., 2019; Cahyono \& Abdullah, 2021). Hal ini merupakan celah penelitian yang menarik untuk dapat ditindaklanjuti dalam penelitian ini.

Penelitian ini difokuskan pada hubungan antara pemimpin abusif dan OCB karyawan. Hal ini penting untuk dilakukan karena masih terdapat inkonsistensi hasil studi terdahulu tentang hubungan antara pemimpin abusif dan OCB. Meskipun pemimpin abusif telah ditemukan dapat menyebabkan rendahnya tingkat OCB karyawan (Zellars et al., 2002; Aryee et al., 2007; Zhao et al., 2013; Decoster et al., 2014; Cahyono et al., 2020b), namun ada hasil studi lain yang menemukan bahwa pemimpin abusif bukan faktor utama yang menyebabkan rendahnya tingkat OCB karyawan, pemimpin abusif ditemukan berpengaruh tidak signifikan pada OCB karyawan (Raferty \& Restubog, 2011; Gregory et al., 2013). Ketidakkonsistenan hasil penelitian tersebut memberikan peluang kepada peneliti untuk memberikan penjelasan secara detail tentang pola hubungan yang terjadi.

Penelitian ini memiliki dua tujuan utama. Pertama, menjelaskan hubungan antara pemimpin abusif dan OCB karyawan. Hal ini didasarkan pada teori pertukaran sosial yang menjelaskan bahwa individu yang diberikan perlakuan buruk oleh pimpinan atau atasannya, cenderung akan membalas perlakuan buruk tersebut dengan tidak menampilkan OCB di perusahaan (Cropanzano \& Mitchell, 2005; Harris et al., 2007; Zhang \& Tsingan, 2013). Kedua, penelitian ini mengusulkan model alternatif dengan mengkonsepkan agreeableness sebagai variabel yang diharapkan dapat memperjelas hubungan antara pemimpin abusif dan OCB. Meskipun beberapa studi terdahulu telah mengusulkan variabel pemoderasi, namun relatif sedikit penelitian yang mengkonsepkan dimensi kepribadian agreeableness sebagai variabel pemoderasi dalam hubungan tersebut. Hal ini dadasarkan pada teori kepribadian yang menjelaskan bahwa individu yang memiliki kepribadian agreeableness yang tinggi, cenderung lebih kuat dalam menghadapi stresor kerja daripada individu dengan kepribadian agreeableness yang rendah (Shih \& Chuang, 2013; Chu et al., 2015; Farhadi et al., 2015). Individu yang memiliki tingkat agreeableness yang tinggi cenderung memiliki sifat dapat bekerjasama, suka menolong dan tidak suka berselisih dengan orang lain, sehingga lebih dapat bertahan dan kuat dalam menghadapi stresor kerja (Comeau \& Griffith, 2005; Ilies et al., 2006; Soepono, 2016; Leephaijaroen, 2016), sehingga cenderung menampilkan OCB yang lebih tinggi ketika mendapatkan perlakuan abusif oleh pimpinanya, begitu pula sebaliknya (Chu et al., 2015; Farhadi et al., 2015). 


\section{TINJAUAN TEORITIS}

\section{A. Hubungan antara Pemimpin Abusif dan Organizational Citizenship Behavior}

Berdasarkan teori pertukaran sosial, pemimpin abusif merupakan salah satu bentuk perlakuan negatif yang diberikan oleh supervisor atau pimpinan kepada bawahan. Hal ini dapat berpotensi memberikan dampak negatif terhadap sikap maupun kinerja karyawan (Cropanzano \& Mitchell, 2005). Pemimpin abusif merupakan perlakuan tidak menyenangkan yang dilakukan oleh pimpinan kepada bawahan yang diekspresikan melalui ejekan, kata-kata kasar, kemarahan, dan perlakuan buruk lainnya (Tepper, 2000). Dalam penelitian ini pemimpin abusif dijelaskan memiliki dampak negatif pada work outcomes karyawan, yaitu dapat menurunkan tingkat OCB karyawan.

Terkait dengan hubungan antara pemimpin abusif dan OCB, hasil studi terdahulu menunjukkan hubungan yang negatif (Zellar et al., 2002; Zhao et al., 2013). Apabila karyawan diperlakukan abusif oleh pimpinannya, maka karyawan akan membalas perlakuan dengan cenderung menunjukkan OCB yang rendah. Karyawan yang merasa diperlakukan abusif akan cenderung untuk menunjukkan kinerja ekstra-role yang rendah. Hal ini dikarenakan karyawan cenderung menghabiskan waktunya untuk mengatasi stres yang dirasakannya, yang berakibat pada penurunan terhadap kinerja karyawan, baik kinerja inrole maupun extra-role (Cahyono, 2013).

Berdasarkan penjelasan teoritis dan regularitas pengaruh antar variabel yang terbentuk, maka hipotesis yang diusulkan dalam penelitian ini adalah sebagai berikut:

H1: Pemimpin abusif berhubungan negatif dengan organizational citizenship behavior.

\section{B. Agreeableness sebagai pemoderasi hubungan antara pemimpin abusif dan organizational citizenship behavior}

Studi terdahulu telah banyak yang mengkaji tentang hubungan antara dimensi kepribadian agreeableness dengan kinerja dan OCB karyawan (Shih \& Chuang, 2013; Chu et al., 2015; Farhadi et al., 2015). Meskipun agreeableness sudah banyak dikaji diberbagai penelitian terdahulu, namun yang mengkonsepkan agreeableness sebagai variabel pemoderasi dalam konteks pemimpin abusif dan OCB masih relatif jarang ditemukan.

Agreeableness merupakan salah satu dimensi kepribadian yang dikonsepkan sebagai variabel pemoderasi dalam penelitian ini. Agreeableness dikonsepkan sebagai variabel yang dapat memberikan penjelasan secara detail tentang hubungan antara pemimpin abusif dan OCB karyawan. Individu yang memiliki dimensi kepribadian agreeableness yang tinggi dan rendah akan menampilkan sikap maupun perilaku yang berbeda ketika mendapatkan perlakuan abusif oleh pimpinannya, hal ini didasarkan pada teori kepribadian (Comeau \& Griffith, 2005; Ilies et al., 2006; Leephaijaroen, 2016). Individu yang memiliki dimensi kepribadian agreeableness yang tinggi cenderung lebih tahan dan kuat ketika menghadapi perlakuan kasar oleh atasannya, sedangkan individu yang memiliki dimensi kepribadian agreeableness yang rendah cenderung minder dan bahkan stres ketika diperlakukan kasar oleh pimpinannya (Chu et al., 2015; Farhadi et al., 2015).

Berdasarkan penjelasan teoritis dan regularitas pengaruh antar variabel yang terbentuk, maka hipotesis yang diusulkan dalam penelitian ini adalah sebagai berikut:

H2: Agreeableness memoderasi hubungan antara pemimpin abusif dan organizational citizenship behavior

\section{III.METODE PENELITIAN}

\section{A. Sampel dan Prosedur}

Responden yang digunakan dalam penelitian ini berjumlah 200 orang karyawan yang bekerja pada Bank Perkreditan Rakyat di Wilayah Surakarta. Teknik purposive sampling digunakan untuk memilih responden. Metode ini digunakan supaya mendapatkan informasi yang sesuai dengan tujuan penelitian. Kriteria sampel dalam penelitian ini adalah sebagai berikut: 1 . Memiliki supervisor atau pimpinan dalam bekerja, 2. Telah menjadi karyawan tetap, 3. Telah bekerja minimal 1 tahun. Pengumpulan data dilakukan dengan menggunakan kuesioner online. Untuk mendorong partisipasi responden, kami memberikan reward kepada responden yang berpartisipasi.

\section{B. Pengukuran Variabel}

Pemimpin Abusif. Pemimpin abusif merupakan variabel independen dalam penelitian ini. Variabel pemimpin abusif diukur dengan menggunakan 5 indikator yang diadopsi dari Tepper (2000) dan Mitchell \& Ambrose (2007). Indikator tersebut adalah sebagai berikut: 1. Ejekan, 2. Cemoohan, 3. Menjatuhkan, 4. Berkomentar negatif, 5. Berkata kasar.

Organizational citizenship behavior. Organizational citizenship behavior merupakan variabel dependen dalam penelitian ini. Variabel organizational citizenship behavior diukur dengan menggunakan 7 item yang diadopsi dari William \& Anderson (1991). Indikator tersebut adalah sebagai berikut: 1. Sukarela membantu pekerjaan teman, 2. Sukarela membantu teman yang memiliki beban kerja berat, 3. Sukarela membantu supervisor/atasan, 4. Sukarela membantu permasalahan rekan kerja, 5. Sukarela membantu rekan kerja baru, 6. Mengutamakan kepentingan orang lain, 7. Sukarela sharing informasi dengan rekan kerja. 
Website : http://ekomaks.unmermadiun.ac.id

Agreeableness. Agreeableness merupakan variabel moderator dalam penelitian ini. Variabel agreeableness diukur dengan menggunakan 6 indikator yang diadopsi dari berbagai penelitian (McCrae \& Costa, 1987; Goldberg, 1990; McCrae \& John, 1992). Indikator tersebut adalah sebagai berikut: 1. Sifat dapat bekerja sama, 2. Dapat dipercaya, 3. Penuh perhatian, 4. Baik hati, 5. Suka menolong, 6. Tidak suka berselisih dengan orang lain.

Ketiga variabel tersebut diukur dengan menggunakan skala likert lima poin $(1=$ sangat tidak setuju sampai $5=$ sangat setuju).

\section{IV.ANALISIS DAN PEMBAHASAN}

\section{A. Deskripsi Profil Responden}

Tabel 1 menjelaskan deskripsi profil responden. Jumlah responden yang berusia 22-30 tahun sebesar 42.5 persen, 31-40 tahun sebesar 50 persen, 41-50 tahun sebesar 5 persen, dan diatas 50 tahun sebesar 2.5 persen. Jumlah responden laki-laki sebesar 20 persen, dan perempuan 80 persen. Tingkat pendidikan responden menunjukkan bahwa 25 persen berpendidikan SMA/SMK, 10 persen berpendidikan D3, dan 65 percen berpendidikan S1. Sejumlah 85 persen responden sudah menikah, dan sisanya 15 persen belum menikah.

\begin{tabular}{lc}
\multicolumn{2}{c}{ Tabel 1. Profil Responden } \\
\hline Variabel & $\begin{array}{c}\text { Presentase (\%) } \\
\text { N = 200 }\end{array}$ \\
\hline Usia (Tahun) & 2.5 \\
$>50$ & 5 \\
$41-50$ & 50 \\
$31-40$ & 42.5 \\
$22-30$ & \\
Jenis Kelamin & 20 \\
Laki-laki & 80 \\
Perempuan & \\
Tingkat Pendidikan & 65 \\
S1 & 10 \\
D3 & 25 \\
SMA/SMK & \\
Status Pernikahan & 85 \\
Menikah & 15 \\
Belum Menikah &
\end{tabular}

\section{B. Hasil Pengujian Hipotesis Penelitian}

Penelitian ini melakukan uji korelasi untuk mengidentifikasi hubungan antar variabel yang diteliti. Hasil uji korelasi antara pemimpin abusif dan OCB ditemukan berkorelasi negatif dan signifikan $(\mathrm{r}=-.171 ; p=<0.05)$. Selanjutnya, agreeableness memiliki korelasi positif dan signifikan pada OCB $(\mathrm{r}=.390 ; p=<0.01)$.

Analisis regresi dilakukan untuk menguji hipotesis yang diformulasikan. Pengujian terhadap hipotesis pertama ditemukan bahwa pemimpin abusif berpengaruh negatif dan signifikan pada OCB $(B=-.123 ; p<0.05)$ (Lihat Tabel 2). Berdasarkan hasil tersebut, secara statistika dapat disimpulkan bahwa hipotesis 1 dalam penelitian ini dinyatakan didukung. Hal ini berarti bahwa individu yang menerima perlakuan abusif oleh pimpinannya cenderung menampilkan tingkat OCB yang rendah. Selanjutnya, serangkaian pengujian dengan menggunakan analisis regresi berjenjang juga dilakukan untuk mengetahui potensi agreeableness sebagai variabel pemoderasi pada hubungan antara pemimpin abusif dan OCB karyawan. Penelitian ini melakukan tiga langkah proses regresi. Langkah pertama, dengan memasukkan variabel agreeableness. Kedua, dengan memasukkan variabel pemimpin abusif. Terakhir, dengan memasukkan variabel interaksi (perkalian skor agreeableness dan OCB). Tabel 2 menunjukkan bahwa hasil pengujian regresi dengan menggunakan interaksi (agreeableness dan OCB) ditemukan berpengaruh positif dan signifikan $(B=.158 ; p<0.01)$. Oleh karena itu, berdasarkan data statistika dapat disimpulkan bahwa hipotesis 2 dalam penelitian ini dinyatakan didukung, agreeableness terbukti sebagai variabel pemoderasi hubungan antara pemimpin abusif dan OCB. Hal ini berarti bahwa agreeableness dapat memperkuat hubungan antara pemimpin abusif dan OCB. Pengaruh tersebut lebih kuat pada individu memiliki agreeableness yang tinggi daripada individu yang memiliki agreeableness yang rendah. 
Website : http://ekomaks.unmermadiun.ac.id

Tabel 2. Hasil Pengujian Hipotesis Penelitian

\begin{tabular}{|c|c|c|c|}
\hline & & OCB & \\
\hline & $\mathbf{R}^{2}$ & $\mathbf{F}$ & $\boldsymbol{B}$ \\
\hline Pengujian Hipotesis 1 & & & \\
\hline Pemimpin Abusif & .029 & $5.999 *$ & $-.123 *$ \\
\hline Pengujian Hipotesis 2 & & & \\
\hline Langkah 1 & & & \\
\hline Agreeableness & .152 & $35.491 * *$ & $.465^{* *}$ \\
\hline Langkah 2 & & & \\
\hline Agreeableness & .169 & $20.098 * *$ & $.449 * *$ \\
\hline Pemimpin Abusif & & & $-.095^{*}$ \\
\hline Lankah 3 & & & \\
\hline Agreeableness & .199 & $16.276 * *$ & -.105 \\
\hline Pemimpin Abusif & & & $-.726 * *$ \\
\hline Pemimpin Abusif x Agreeableness & & & $.158 * *$ \\
\hline
\end{tabular}

Keterangan: $* p<0.05 ; * * p<0.01$

Sumber: Data primer yang diolah, 2021

\section{Pembahasan}

Studi ini memiliki dua tujuan utama. Pertama, untuk menginvestigasi hubungan antara pemimpin abusif dan OCB. Kedua, untuk mengetahui peran agreeableness sebagai pemoderasi hubungan antara pemimpin abusif dan OCB karyawan. Hasil penelitian ini memberikan dukungan terhadap hipotesis pertama yang mengindikasi hubungan negatif dan signifikan antara pemimpin abusif dan OCB, artinya bahwa karyawan yang lebih sering menerima perlakuan abusif oleh pimpinannya, cenderung memiliki tingkat OCB yang rendah, begitu pula sebaliknya. Hal ini bersesuaian dengan teori pertukaran sosial yang menyatakan bahwa ketika seseorang diberikan perlakuan buruk oleh orang lain, maka individu tersebut akan membalas dengan perilaku yang buruk pula (Cropanzano \& Mitchell, 2005; Harris et al., 2007). Artinya bahwa karyawan yang merasa diperlakukan abusif oleh atasannya, cenderung membalas perlakuan tersebut dengan menampilkan OCB yang rendah (Zellar et al., 2002; Zhao et al., 2013).

Hasil studi juga menemukan dukungan terhadap hipotesis kedua, yang menegaskan bahwa agreeableness dapat memoderasi hubungan antara pemimpin abusif dan OCB karyawan. Hal ini mengindikasi bahwa individu dengan tingkat agreeableness tinggi dan rendah cenderung menampilkan OCB yang berbeda ketika mereka menerima perlakuan abusif dari pimpinannya (Chu et al., 2015; Farhadi et al., 2015). Hasil penelitian ini bersesuaian dengan teori kepribadian yang menjelaskan bahwa individu akan memberikan pola perilaku yang berbeda tergantung pada jenis dimensi kepribadian yang dimilikinya dalam menghadapi stresor dan perilaku negatif yang diterimanya (Comeau \& Griffith, 2005; Ilies et al., 2006; Leephaijaroen, 2016).

Karyawan yang memiliki dimensi kepribadian agreeableness yang tinggi cenderung lebih tahan dan lebih kuat ketika mendapatkan perlakuan abusif oleh pimpinannya, sehingga mereka akan tetap merasa nyaman dalam melakukan pekerjaannya bahkan tetap menampilkan OCB yang tetap tinggi. Sedangkan karyawan yang memiliki dimensi kepribadian agreeableness rendah cenderung menganggap perlakuan abusif sebagai perilaku yang negatif yang dapat membuat mereka menjadi tidak bersemangat dalam bekerja bahkan sampai mengalami stres kerja. Karyawan yang memiliki tingkat agreeableness yang rendah cenderung lebih mudah stres dan tidak tahan terhadap perlakuan kasar yang diberikan oleh pimpinannya, sehingga mereka cenderung untuk menutup diri dan menampilkan OCB yang rendah.

\section{KESIMPULAN DAN SARAN}

Studi ini menggarisbawahi bahwa pemimpin abusif berhubungan negatif dan signifikan pada OCB karyawan. Penelitian ini menggunakan teori pertukaran sosial sebagai dasar untuk memberikan penjelasan tentang hubungan tersebut. Penelitian ini juga menemukan bahwa agreeableness memoderasi hubungan antara pemimpin abusif dan OCB karyawan. Penelitian ini menggunakan teori kepribadian sebagai dasar untuk menjelaskan hubungan tersebut. Temuan dalam penelitian ini memberikan penjelasan bahwa karyawan yang memiliki dimensi kepribadian agreeableness yang tinggi dan rendah memberikan pola perilaku yang berbeda ketika mereka menerima perlakuan abusif dari pimpinan atau atasannya.

Secara teoritis, penelitian ini dapat memberikan kontribusi terhadap pengembangan teori terkait dengan konsep pemimpin abusif. Pertama, memberikan penjelasan secara teoritis terkait hubungan antara pemimpin abusif dan OCB karyawan. Kedua, memberikan penjelasan secara teoritis tentang peran agreeableness dalam hubungan antara pemimpin abusif dan OCB karyawan.

Selain kontribusi secara teoritis, penelitian ini juga memberikan kontribusi secara praktis. Model konseptual yang diusulkan dalam penelitian ini diharapkan dapat memberikan insight kepada praktisi dalam bidang manajemen sumberdaya manusia 
Website : http://ekomaks.unmermadiun.ac.id

khususnya kepemimpinan. Dalam memberi treatment kepada karyawan untuk menghasilkan OCB yang tinggi, diharapkan para praktisi dapat menggunakan model konseptual yang diusulkan dalam penelitian ini. Pemimpin abusif dapat digunakan sebagai strategi untuk meningkatkan OCB dalam melaksanakan tugas dengan memperhatikan dimensi kepribadian agreeableness karyawan. Apabila hal ini tidak diperhatikan dengan baik oleh para pimpinan, maka dikhawatirkan akan menimbulkan dampak negatif terhadap kinerja karyawan.

\section{VI.DAFTAR PUSTAKA}

Aryee, S., Z.X. Chen., L. Sun., \& Y.A. Debrah. 2007. Antecedents and outcomes of abusive supervision: Test of a trickle-down model. Journal of Applied Psychology. Vol 92, pp 191- 201.

Cahyono, E. 2011. Pengaruh Kepuasan Kerja pada Organizational Citizenship Behaviour (OCB) dengan Komitmen Tim sebagai Variabel Pemoderasi (Studi pada Karyawan PT. PLN (Persero) Apj Surakarta).

Cahyono, E., \& Abdullah, S. 2020 Exploring the Model of Abusive Supervision and Employee's Turnover Intention: Is Neuroticism a Moderator?. In ICAME 2020: Proceedings of the 5th International Conference on Accounting, Management and Economics, ICAME 2020, 14-15 October 2020, Makassar, Indonesia (p. 119). European Alliance for Innovation.

Cahyono, E., Haryono, T., Haryanto, B., \& Harsono, M. 2020. A New Insight in Relation between Abusive Supervision and Work Outcomes: A Conceptual Review. Quality-Access to Success, 21 (177), 26-30. (a)

Cahyono, E., Haryono, T., Haryanto, B., \& Harsono, M. 2020. The Role of Gender in the Relationship Between Abusive Supervision and Employee's Organizational Citizenship Behaviour in Indonesia. International Journal of Trade and Global Markets, 13 (3), 311-322. (b)

Chu, X., Ma, Z., Li, Y., \& Han, J. 2015. Agreeableness, extraversion, stressor and physiological stress response. International Journal of Social Science Studies, 3, 79.

Comeau, D. J., \& Griffith, R. L. 2005. Structural interdependence, personality, and organizational citizenship behavior: An examination of person-environment interaction. Personnel Review.

Cropanzano, R., \& Mitchell, M. S. 2005. Social exchange theory: An interdisciplinary review. Journal of management, 31(6), 874-900.

Decoster, S., J. Camps., \& J. Stouten. 2014. The mediating role of LMX between abusive supervision and work behaviors A replication and extension. American Journal of Business. Vol. 29, No. 1, pp. 61-75.

Farhadi, H., Nasir, R., Omar, F., \& Nouri, A. 2015. Understanding Employees'deviant Behaviour: The Role of Agreeableness and Stress Related to Work. e-Bangi, 12(3).

Goldberg, L. R. 1990. An alternative description of personality-The Big-Five factor structure. Journal of Personality and Social Psychology, 59, 1216-1229

Gregory, B.T., T. Osmonbekov., S.T. Gregory., M.D. Albritton., \& J.C. Car. 2013. Abusive supervision and citizenship behaviors: exploring boundary conditions. Journal of Managerial Psychology. Vol. 28 No. 6, pp. 628- 644.

Hancock, P. 2000. The lived experience of female factory workers in rural West java. Labor and Management in Development Journal, 1(1), 1-18.

Harris, K. J., K.M. Kacmar., \& S. Zivnuska. 2007. An investigation of abusive supervision as a predictor of performance and the meaning of work as a moderator of the relationship. Leadership Quarterly. Vol 18, pp 252- 263.

Haryanto, B., \& Cahyono, E. 2019. Relationship Between Abusive Supervision and Performance: The Role of Gender. European Research Studies Journal, 22 (3), 305-311.

Hofstede, G. 1983. National cultures in four dimensions: A research-based theory of cultural differences among nations. International Studies of Management \& Organization, 13, 46-74.

Ilies, R., Scott, B. A., \& Judge, T. A. 2006. The interactive effects of personal traits and experienced states on intraindividual patterns of citizenship behavior. Academy of Management Journal, 49(3), 561-575.

Jiang, W., Wang, L., \& Lin, H. 2016. The role of cognitive processes and individual differences in the relationship between abusive supervision and employee career satisfaction. Personality and Individual Differences, 99, 155-160.

Leephaijaroen, S. 2016. Effects of the big-five personality traits and organizational commitments on organizational citizenship behavior of support staff at Ubon Ratchathani Rajabhat University, Thailand. Kasetsart Journal of Social Sciences, 37(2), 104-111.

McCrae, R.R., \& Costa-Jr., P.T. 1987. Validation of the five-factor model of personality across instruments and observers. Journal of Personality and Social Psychology, 52(1), 81-90.

McCrae, R.R., \& John, P.O. 1992. An introduction to the five-factor model and its applications. Journal of Personality. 60(2), $175-215$.

Mitchell, M. S., \& M.L. Ambrose. 2007. Abusive supervision and workplace deviance and the moderating effects of negative reciprocity beliefs. Journal of Applied Psychology, 92(4), 1159- 1168.

Pradhan, S., Jena, L.K., \& Mohapatra, M. 2018. Role of gender on the relationship between abusive supervision and employee's intention to quit in indian electricity distribution companies. Gender in Management: An International Journal. 
Website : http://ekomaks.unmermadiun.ac.id

Rafferty, A.E \& S.L.D. Restubog. 2011. The Influence of Abusive Supervisors on Followers' Organizational Citizenship Behaviours: The Hidden Costs of Abusive Supervision. British Journal of Management. Vol. 22, pp 270- 285.

Rodwell, J., Brunetto, Y., Demir, D., Shacklock, K., \& FarrWharton, R. 2014. Abusive supervision and links to nurse intentions to quit. Journal of Nursing Scholarship, 46(5), 357-365.

Shih, C. T., \& Chuang, C. H. 2013. Individual differences, psychological contract breach, and organizational citizenship behavior: A moderated mediation study. Asia Pacific Journal of Management, 30(1), 191-210.

Soepono, D. N., \& Srimulyani, V. A. 2015. Analisis pengaruh the big five personality terhadap Organizational Citizenship Behavior (OCB) dan kinerja perawat di RS Santa Clara Madiun. Jurnal Manajemen Indonesia, 15(1), 51-64.

Tepper, B. J. 2000. Consequences of abusive supervision. Academy of Management Journal, 43, 178- 190.

Tepper, B.J., M.K. Duffy., C.A. Henle., \& L.S. Lambert. 2006. Procedural injustice, victim precipitation, and abusive supervision. Personel Psychology, 59, 101-123.

Tepper, B.J., J.C. Carr., D.M. Breaux., S. Geider., C. Hu., \& W. Hua. 2009. Abusive supervision, intentions to quit, and employees' workplace deviance: A power/dependence analysis. Organizational Behavior and Human Decision Processes, 109, 156- 167.

Williams, L. J., \& Anderson, S. E. 1991. Job satisfaction and organizational commitment as predictors of organizational citizenship and in-role behaviors. Journal of management. Vol 17, No 3, pp 601-617.

Zellars, K., B. Tepper., \& M. Duffy. 2002. Abusive supervision and subordinates' organizational citizenship behavior. Journal of Applied Psychology, 87, 1068- 1076.

Zhang, R.P., Tsingan, L. 2013. Extraversion and neuroticism mediate associations between openness, conscientiousness, and agreeableness and affective well-being. Journal of Happiness Studies, 15(6), 1377-1388.

Zhao, H., Z. Peng., Y. Han., G. Sheard., \& A. Hudson. 2013. Psychological Mechanism Linking Abusive Supervision and Compulsory Citizenship Behavior: A Moderated Mediation Study. The Journal of Psychology. Vol 147 No 2, pp $177-$ 195. 